\title{
Erratum to: Local control and toxicity outcomes in brainstem metastases treated with single fraction radiosurgery: is there a volume threshold for toxicity?
}

\author{
Jeremy M. Kilburn • Thomas L. Ellis • James F. Lovato • \\ James J. Urbanic $\cdot$ J. Daniel Bourland $\cdot$ Michael T. Munley \\ Allan F. deGuzman • Kevin P. McMullen • Edward G. Shaw • \\ Stephen B. Tatter - Michael D. Chan
}

Published online: 19 September 2014

(C) Springer Science+Business Media New York 2014

Erratum to: J Neurooncol (2014) 117:167-174

DOI 10.1007/s11060-014-1373-x

The fifth author's family name was shown incorrectly in the original publication. It is correct in this erratum.

The online version of the original article can be found under doi:10.1007/s11060-014-1373-x.

J. M. Kilburn ( () J. J. Urbanic · J. D. Bourland .

M. T. Munley · A. F. deGuzman · K. P. McMullen ·

E. G. Shaw - M. D. Chan

Department of Radiation Oncology, Wake Forest School of

Medicine, 1 Medical Center Blvd, Winston-Salem,

NC 27157, USA

e-mail: jkilburn@wakehealth.edu

T. L. Ellis - S. B. Tatter

Department of Neurosurgery, Wake Forest School of Medicine,

Winston-Salem, NC, USA

J. F. Lovato

Division of Public Health Sciences, Wake Forest School of

Medicine, Winston-Salem, NC, USA 